\title{
The Orexin/Hypocretin System in Zebrafish Is Connected to the Aminergic and Cholinergic Systems
}

\author{
Jan Kaslin, ${ }^{1}$ Johanna M. Nystedt, ${ }^{1,2}$ Maria Östergård, ${ }^{1}$ Nina Peitsaro, ${ }^{2}$ and Pertti Panula ${ }^{1,2}$ \\ 'Department of Biology, Åbo Akademi University, Biocity, FIN-20520 Turku/Åbo, Finland, and ${ }^{2}$ Neuroscience Center and Institute of Biomedicine, FIN- \\ 00014 University of Helsinki, Helsinki, Finland
}

The orexin/hypocretin (ORX) system is involved in physiological processes such as feeding, energy metabolism, and the control of sleep and wakefulness. The ORX system may drive the aminergic and cholinergic activities that control sleep and wakefulness states because of the ORX fiber projections to the aminergic and cholinergic cell clusters. The biological mechanisms and relevance of the interactions between these neurotransmitter systems are poorly understood. We studied these systems in zebrafish, a model organism in which it is possible to simultaneously study these systems and their interactions.

We cloned a zebrafish prepro-ORX gene that encodes for the two functional neuropeptides orexin-A (ORX-A) and orexin-B (ORX-B). The prepro-ORX gene of the zebrafish consisted of one exon in contrast to mammals. The sequence of the ORX-A peptide of the zebrafish was less conserved than the ORX-B peptide compared with other vertebrates. By using in situ hybridization and immunohistochemistry, we found that the organization of the ORX system of zebrafish was similar to the ORX system in mammals, including a hypothalamic cell cluster and widespread fiber projections. The ORX system of the zebrafish showed a unique characteristic with an additional putatively ORX-containing cell group. The ORX system innervated several aminergic nuclei, raphe, locus ceruleus, the mesopontine-like area, dopaminergic clusters, and histaminergic neurons. A reciprocal relationship was found between the ORX system and several aminergic systems. Our results suggest that the architecture of these neurotransmitter systems is conserved in vertebrates and that these neurotransmitter systems in zebrafish may be involved in regulation of states of wakefulness and energy homeostasis by similar mechanisms as those in mammals.

Key words: teleost; Danio rerio; histamine; serotonin; dopamine; noradrenaline; acetylcholine; narcolepsy

\section{Introduction}

The orexin/hypocretin peptides orexin-A (ORX-A) and orexin-B (ORX-B) are derived from the proteolysis of a peptide precursor, prepro-ORX. The production of ORX peptides in mammals is limited to neurons in the lateral hypothalamic area, and ORX fibers are widespread in most areas of the mammalian brain. High densities of ORX fibers have been found in aminergic and cholinergic nuclei (Peyron et al., 1998). The actions of the ORX system are mediated through two G-protein-coupled receptors, orexin $1\left(\mathrm{ORX}_{1} \mathrm{R}\right)$ and orexin2 $\left(\mathrm{ORX}_{2} \mathrm{R}\right)$ (Sakurai et al., 1998). The noradrenergic neurons predominantly express $\mathrm{ORX}_{1} \mathrm{R}$, whereas histaminergic and cholinergic neurons express $\mathrm{ORX}_{2} \mathrm{R}$, and the serotonergic neurons express both types (Trivedi et al., 1998; Marcus et al., 2001). Consequently, the ORX-containing cell group provides a significant input to these systems. However,

Received Aug. 12, 2003; revised Jan. 15, 2004; accepted Jan. 19, 2004.

This work was supported by the Academy of Finland, the Sigrid Juselius Foundation, and the Magnus Ehrnrooth Foundation. We thank Dr. A. F. Parlow (National Hormone and Peptide Program of National Institute of Diabetes and Digestive and Kidney Diseases) for providing prolactin and prolactin antisera. We also thank Jari Korhonen and Levente Basco for excellent technical assistance.

Correspondence should be addressed to Pertti Panula, Department of Biology, Åbo Akademi University, Tykistökatu 6 a, Biocity, FIN-20520 Turku/Åbo, Finland. E-mail: ppanula@abo.fi.

DOI:10.1523/JNEUROSCI.4908-03.2004

Copyright $\odot 2004$ Society for Neuroscience $\quad$ 0270-6474/04/242678-12\$15.00/0 little is known about aminergic and cholinergic inputs to the ORX system.

The molecular structure of the ORX peptides is highly conserved among the vertebrates (Sakurai et al., 1998; Shibahara et al., 1999; Alvarez and Sutcliffe, 2002; Ohkubo et al., 2002). On the basis of a few studies in non-mammalian vertebrates, the general organization of the ORX system of the brain seems to be conserved among vertebrates (Shibahara et al., 1999; Galas et al., 2001; Ohkubo et al., 2002). The zebrafish has become known as an excellent model organism for studies of vertebrate biology and particularly in studies of vertebrate genetics and embryonal development (Balter, 1995; Haffter et al., 1996). It is also a potential model for human diseases and drug screening (Dooley and Zon, 2000; Fishman, 2001).

A dysfunctional ORX system leads to narcolepsy in humans and dogs, even if the cause is different. Narcoleptic humans have a clearly lowered number of ORX neurons and reduced ORX content in the CSF, whereas mutations in the $\mathrm{ORX}_{2} \mathrm{R}$ induce narcolepsy in dogs (Beuckmann and Yanagisawa, 2002; Sutcliffe and de Lecea, 2002). Although a deficient ORX system is the main cause of narcolepsy, the biological mechanisms of how the ORX system is involved in narcolepsy are poorly understood. It has been proposed that the ORX system drives the aminergic and cholinergic activity to control sleep and wakefulness states because of its widespread projections to the aminergic and cholin- 
ergic cell clusters (Kilduff and Peyron, 2000; Saper et al., 2001). In addition to its importance to the sleep-wake cycle and arousal, the ORX system is also involved in physiological processes such as feeding, energy metabolism, and autonomic functions (Beuckmann and Yanagisawa, 2002).

The connections of the ORX system with the major activating systems have not been studied systematically in any species. Here, we identify and characterize the ORX system in zebrafish by cloning the prepro-ORX gene, studying the anatomical distribution of mRNA expression and ORX immunoreactivity and their relationships to the aminergic and cholinergic systems. Our findings are useful for genetic and chemical screens that are targeted toward finding genes and mechanisms related to ascending activation systems involved in basic physiological processes and suggest that zebrafish is a potential model of human CNS disorders in studies on activating peptidergic and aminergic systems.

\section{Materials and Methods}

Preparation of tissue and immunohistochemistry. Zebrafish (Danio rerio) larvae and adults from outbred and $\mathrm{AB}$ strains of both sexes were used for the study. The fish were kept at $28^{\circ} \mathrm{C}$ with a $14 / 10 \mathrm{hr}$ light/dark cycle according to Westerfield (1995). The permit to conduct these experiments was obtained from the Committee for Animal Experiments of Abo Akademi University in agreement with the ethical guidelines of the European Convention in Strasbourg (1986).

The immunohistochemistry (IHC) protocols have been used and described in detail previously (Kaslin and Panula, 2001). Dissected brains were immersion fixed in 2\% 1-ethyl-3-(3-dimethyl-aminopropyl)carbodiimide (EDAC) (Sigma, St. Louis, MO) and $0.4 \%$ $\mathrm{N}$-hydroxysuccinimide (Sigma), dissolved in $0.1 \mathrm{M}$ phosphate buffer (PB), $\mathrm{pH} 7.4$, at $4^{\circ} \mathrm{C}$ for $10-14 \mathrm{hr}$, or alternatively fixed in $2 \%$ paraformaldehyde (PFA) in PB. The brains were transferred to sucrose $(20 \%$ in $0.1 \mathrm{M} \mathrm{PB}$ ) and kept for an additional $10-14 \mathrm{hr}$ at $4^{\circ} \mathrm{C}$, followed by freezing and embedding (M-1 embedding matrix 1310; Lippshaw, Pittsburgh, PA). The brains were cryosectioned $(20-30 \mu \mathrm{m})$, and the sections were collected on gelatin-coated slides. The sections were washed with $0.25 \%$ Triton X-100 in PBS, pH 7.4 (PBS-T), and incubated for $12 \mathrm{hr}$ at $4^{\circ} \mathrm{C}$ with primary antisera. The following primary antisera were used: rabbit antisera against histamine (19 C) (Panula et al., 1990) diluted 1:10,000-1: 20,000, mouse monoclonal anti-tyrosine hydroxylase $(\mathrm{TH})$ diluted 1:2000-1:5000 (Diasorin, Stillwater, MN), mouse monoclonal antiserotonin diluted 1:100-1:250 (Dako, Glostrup, Denmark), rabbit antiserum against 5-HT diluted 1:4000-1:6000 (Diasorin), goat serum against ORX-A (1:000; Santa Cruz Biotechnology, Santa Cruz, CA), rabbit serum against ORX-A (1:000; Chemicon, Temecula, CA), goat serum against ORX-B (1:1000; Santa Cruz Biotechnology), rabbit serum against prepro-ORX (1:1000; Chemicon), rabbit serum against mouse prolactin [1:5000; National Hormone and Peptide Program of the National Institute of Diabetes and Digestive and Kidney Diseases (NIDDK), Torrance, CA], rabbit serum against rat prolactin (1:5000; National Hormone and Peptide Program of NIDDK), and goat serum against choline acetyltransferase (ChAT) (1:200; Chemicon). After the incubation with the primary antisera, the sections were washed several times in PBS-T and incubated for $1 \mathrm{hr}$ at room temperature with Alexa 488- and Alexa 568conjugated secondary antibodies (1:500; Molecular Probes, Eugene, OR). The slides were thoroughly washed and mounted with glycerol/PBS (1:1).

Specificity controls of the used ORX-A antisera were done by preincubating the primary antisera with $0.1-10 \mu \mathrm{M}$ mammalian ORX-A peptide (Bachem, Bubendorf, Switzerland), mammalian ORX-B peptide (Bachem), recombinant mouse prolactin (National Hormone and Peptide Program of NIDDK), and in ORXA conserved peptide fragments SCRLY (Ser-Cys-Arg-Leu-Tyr) and GILTL-NH ${ }_{2}$ (Gly-Ile-Leu-Thr-Leu$\mathrm{NH}_{2}$ ) (custom synthesized by Peptide Technologies, Gaithersburg, MD) for $24 \mathrm{hr}$ under slow stirring at $4^{\circ} \mathrm{C}$. Negative controls done by omitting primary or secondary antibody from the staining protocol produced no staining.
The specimens were examined, and images were taken with a DM RXA epifluorescence microscope (Leica Microsystems Semiconductor GmBH, Wetzlar, Germany) and a TCS SP confocal microscopy system (Leica). The emission wavelength area for Alexa 488 was $495-550 \mathrm{~nm}$, and, for Alexa 568, it was $600-750 \mathrm{~nm}$. To minimize cross talk between the green (Alexa 488) and the red (Alexa 568) channels in double-stained specimens, the channels were scanned separately (sequential scanning). The fluorophores were excited with the 488 or $568 \mathrm{~nm}$ lines from an argon-krypton laser (Omnichrome; Melles Griot, Carlsbad, CA). Acquired images were edited with Adobe Photoshop 6.01 (Adobe Systems, San Jose, CA) and compiled with Corel Draw 9.0 software (Corel, Ottawa, Ontario, Canada).

Cloning, sequence analysis, reverse transcription-PCR, and in situ hybridization. To clone the zebrafish prepro-ORX gene, zebrafish wholebrain total RNA was isolated with RNAwiz (Ambion, Austin, TX), and 5 $\mu \mathrm{g}$ of total RNA was reverse transcribed with the SuperScript FirstStrand cDNA synthesis kit (Invitrogen, Carlsbad, CA). Conventional reverse transcription (RT)-PCR was conducted with an annealing temperature of $57^{\circ} \mathrm{C}$ and a total of 45 cycles with the sense primer $5^{\prime}$-AAT GCG CCT CTG TCG ACA TTG-3' and antisense primer 5' -ACT GTC CAC ATC CTG TGG TAC CG-3', which were designed from the sequence information in the genomic contig BX005093 (Sanger Institute, The Wellcome Trust, Cambridge, UK). A negative control was included in which template cDNA was omitted and was replaced with water. The PCR products were analyzed by agarose gel electrophoresis, and a band of the expected size of $\sim 450$ bp was excised from the gel and purified (Minelute gel extraction kit; Qiagen, Hilden, Germany). The purified PCR product was ligated into pGEM-T easy vector (Promega, Madison, $\mathrm{WI}$ ), and recombinant clones were isolated for subsequent sequencing analysis. Several clones were sequenced to yield a consensus sequence. A base pair of 457 of the zebrafish prepro-ORX gene was cloned, encoding an open-reading frame of 152 amino acid (aa) residues, including the start methionine. To assemble the complete open-reading frame, including the stop triplet, the missing $27 \mathrm{bp}$ of the $3^{\prime}$-end of the zebrafish prepro-ORX gene were derived from the genomic contig BX005093.

The regional distribution of prepro-ORX mRNA expression was studied with both RT-PCR and in situ hybridization (ISH). For RT-PCR, total RNA from tissues (forebrain, midbrain, hindbrain, liver, intestines, heart, gills, and muscle) pooled from seven zebrafish was isolated and reverse transcribed as described above. The brain was dissected into three pieces according to easily identifiable anatomical landmarks (see Fig. $1 E$ ). The forebrain part included the telencephalon and the preoptic region, whereas the midbrain part consisted of diencephalon and mesencephalon, and the hindbrain part consisted of the rhombencephalon. The cDNA was subjected to PCR with an annealing temperature of $66^{\circ} \mathrm{C}$ for the prepro-ORX gene and $59^{\circ} \mathrm{C}$ for the $\beta$-actin gene for 30 cycles. The prepro-ORX forward primer 5'-ATG GCG CTG CTC GCT CAC CT-3' and reverse primer $5^{\prime}$-AGC GGG CTC CTC CAG CCT CTT CC-3' were designed to amplify a $297 \mathrm{bp}$ fragment of the cloned zebrafish preproORX gene, and the zebrafish $\beta$-actin forward primer $5^{\prime}$-TGT GGC CCT TGA CTT TGA GCA G-3' and reverse primer $5^{\prime}$-TAG AAG CAT TTG CGG TGG ACG A-3' were designed to amplify a 474 bp fragment on the basis of the sequence in GenBank accession number AF025305. The PCR products were analyzed by ethidium bromide agarose gel electrophoresis. To control genomic DNA contamination, a cDNA reaction mixture omitting reverse transcriptase was prepared. A negative control with water as template was included. For the phylogenetic studies, the preproORX sequences were aligned using the ClustalW method. Manual editing of the sequences was performed using GeneDoc software (http://www.psc.edu/biomed/genedoc/). The sequences used for construction of the phylogenetic tree were amino acid sequences from an 8 aa upstream of peptide $\mathrm{A}$ to the end of peptide $\mathrm{B}$, because these regions are most conserved. The spacer sequences in the ORX-A sequence in the zebrafish and Fugu rubripes sequences were also excluded from the analysis. A maximum parsimony tree was drawn using MEGA2.1 software (http://www.megasoftware.net/). Gaps were treated as data, and the strength of the tree topology was tested by bootstrap analysis using 1000 replicates.

For the in situ hybridization experiments, an oligonucleotide probe was designed to recognize the spacer region of the prepro-ORX mRNA. 
The sequence of the probe was 5'-CGT TGT TGA GAT GCA CTA AAT GTC TGG CGA CGG AAG AGT CGT TTC TGC GT-3' . A 100fold excess of an unlabeled specific probe was used to block binding of the labeled probe in control samples. The hybridization procedure used has been described previously (Nieminen et al., 2002). The hybridization was done overnight in a humidified chamber at $44^{\circ} \mathrm{C}$. Sections were exposed to BioMax x-ray films (Eastman Kodak, Rochester, NY) for $14 \mathrm{~d}$.

For the cellular localization of prepro-ORX mRNA expression, in situ hybridization with a prepro-ORX riboprobe (457 bp) was performed. Brains were fixed in $4 \%$ PFA in PB for $14-16 \mathrm{hr}$ at $4^{\circ} \mathrm{C}$, immersed in $20 \%$ sucrose, and frozen. Cryosections $(10-18 \mu \mathrm{m})$ were collected on poly-L-lysine-coated slides (Gerhard Menzel Glasbearbeitungswerk, Braunschweig, Germany). Thawed and dried slides were fixed in $4 \%$ PFA, permeabilized with proteinase $\mathrm{K}$ (1 $\mu \mathrm{g} / \mathrm{ml}$ in PBS plus $0.1 \%$ Tween 20 ), postfixed, treated with $0.1 \mathrm{M}$ triethanolamine- $0.25 \%$ acetic anhydride, and finally rinsed in $5 \times$ SSC. Digoxenin (DIG) RNA probes were synthesized from a plasmid containing the $457 \mathrm{bp}$ cloned zebrafish prepro-ORX gene linearized with SalI (antisense) or ApaI (sense) using T7 and SP6 polymerase, respectively (Roche Products, Mannheim, Germany). The probes were purified with the RNeasy MinElute cleanup kit (Qiagen). The sections were prehybridized for 1 hr at $65^{\circ} \mathrm{C}$ in hybridization buffer $[50 \%$ deionized formamide, $10 \%$ dextran sulfate, $1 \times$ Denhardt's solution, $50 \mathrm{~mm}$ dithiotreitol, $100 \mu \mathrm{g} / \mathrm{ml}$ yeast tRNA (Roche Products), $500 \mu \mathrm{g} / \mathrm{ml}$ salmon sperm DNA, $300 \mathrm{~mm} \mathrm{NaCl}, 10 \mathrm{~mm}$ Tris$\mathrm{HCl}, \mathrm{pH}$ 7.5, $5 \mathrm{~mm}$ EDTA, and $10 \mathrm{~mm}$ $\mathrm{NaH}_{2} \mathrm{PO}_{4}$ ]. Hybridization with $\sim 300 \mathrm{ng} / \mathrm{ml}$ probe was performed for $14-16 \mathrm{hr}$ at $65^{\circ} \mathrm{C}$. Posthybridization washes were as follows: $66 \%$ wash 1 solution ( $50 \%$ formamide, $5 \times$ SSC, $0.1 \%$ Tween $20,0.092 \mathrm{M}$ citric acid); $33 \% 2 \times$ SSC for 5 min at $65^{\circ} \mathrm{C}, 66 \% 2 \times$ SSC; $33 \%$ wash 1 solution for $5 \mathrm{~min}$ at $65^{\circ} \mathrm{C}, 2 \times \mathrm{SSC}$ for $5 \mathrm{~min}$ at $65^{\circ} \mathrm{C}, 0.2 \times$ SSC plus $0.1 \%$ Tween 20 for 20 min at $65^{\circ} \mathrm{C}, 0.1 \times$ SSC plus $0.1 \%$ Tween 20 for two times for $20 \mathrm{~min}$ each at $65^{\circ} \mathrm{C}, 50 \%$ MABT ( $100 \mathrm{~mm}$ maleic acid, 150 $\mathrm{mm} \mathrm{NaCl}$, pH 7.5, and $0.1 \%$ Tween 20); $50 \% 0.2 \times$ SSC for $5 \mathrm{~min}$ at room temperature; and finally in MABT for $5 \mathrm{~min}$ at room temperature. The slides were blocked with $2 \%$ blocking solution (Roche Products) in MABT for $1 \mathrm{hr}$ at room temperature, followed by incubation in alkaline phosphatase-conjugated anti-DIG goat antibody (Roche Products) diluted 1:1000 in blocking solution for $2 \mathrm{hr}$ at room temperature. After washing four times for $10 \mathrm{~min}$ each in MABT and two times for $10 \mathrm{~min}$ each in coloration buffer (CB) (100 mu Tris- $\mathrm{HCl}, \mathrm{pH}$ 9.5, $50 \mathrm{~mm} \mathrm{MgCl}_{2}$, $100 \mathrm{~mm} \mathrm{NaCl}$, and $0.1 \%$ Tween 20), the sections were incubated with 4-nitroblue tetrazolium chloride/5-bromo-4-chloro-3-indolyl phosphate (Roche Products) in $\mathrm{CB}$ for $16-48 \mathrm{hr}$ at $4^{\circ} \mathrm{C}$. The sections were washed in PBS plus $0.1 \%$ Tween 20, fixed in $4 \%$ PFA in PB, rewashed, and mounted in 30\% PBS-70\% glycerol.

\section{Results}

\section{The structure of zebrafish ORXs compared with mammalian ORXs}

By combining the tblastn algorithm (National Center for Biotechnology Information) and the gene prediction software Genscan (http://genes.mit.edu/GENSCAN.html), we found a genomic

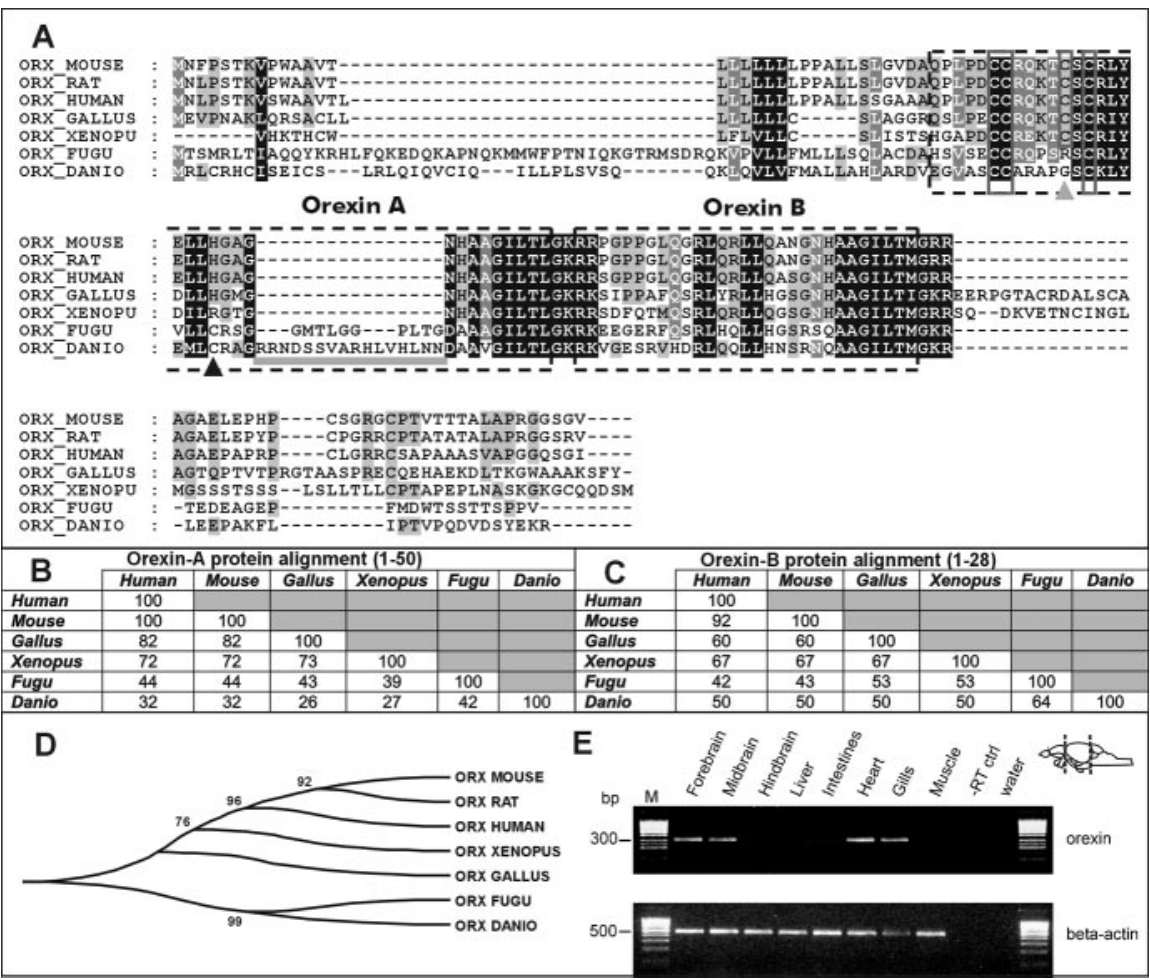

Figure 1. A, Alignment of the ORX sequences from the human (Homo sapiens), mouse (Mus musculus), rat (Rattus norvegicus), (D. rerio), chicken (Gallus gallus), frog (Xenopus laevis), and pufferfish (F. rubripes). The zebrafish and pufferfish seresidues are boxed, and the missing cysteine residues are indicated with a gray arrowhead. Both fish sequences have an additiona cysteine residue in position 19 that is not found in the other vertebrate (black arrowhead). Both the zebrafish and the pufferfish sequences contain a spacer region within the ORX-A sequence; the spacer sequence is underlined (thick gray line). The peptide sequences are boxed with dashed lines. The human, mouse, rat, and chicken sequences used were obtained from Swiss-Prot (ORX_HUMAN, ORX_MOUSE, ORX_RAT, ORX_GALLUS), the frog sequence is from the article by Shibahara et al. (1999), and the between the ORX peptides at the amino acid level. The spacer region that is found only in the fish sequences was excluded from the alignment. The $O R X$ peptide amino acid sequences from different vertebrates are compared and given as percentage identity of $O R X-A(B)$ and ORX-B ( ()$. D$, An unrooted maximum parsimony phylogenetic tree of the ORX exon2 sequences. The tree shows topology only, not ces. The numbers at the nodes indicate the percentage of bootstrap replicates in which the node was retained. E, Regional expression idbrain, heart, and gills. $\beta$-Actin was used as control to verify the integrity of all CDNA. The schematic drawing found in the top right corner shows how the brains were dissected. M, Molecular marker.

zebrafish contig (BX005093) containing a potential zebrafish prepro-ORX gene. The potential zebrafish prepro-ORX gene was encoded by a single exon in contrast to other known prepro-ORX genes. The gene sequence was verified by molecular cloning. Both the $\mathrm{C}$-terminal part and $\mathrm{N}$-terminal part of the prepro-ORX peptide showed a high degree of variation between zebrafish and mammals. However, the ORX peptide sequences in zebrafish showed a high degree of conservation to other vertebrate sequences (pufferfish, frog, chick, and mammals) (summarized in Fig. 1). Overall, the structure of the peptide sequence for ORX-B was more conserved in vertebrates than the peptide sequence of ORX-A. The zebrafish ORX peptides showed the highest sequence homology to the tetraodontiform fish Fugu rubripes, followed by amoderate homology to the other vertebrates. The zebrafish ORX-A was a 47 aa residue peptide, and it showed the highest homology to Fugu (42\%). The predicted peptide was Nterminally 2 aa shorter than its mammalian counterparts. The zebrafish ORX-B was a 28 aa residue peptide, and it showed a $64 \%$ identity with the Fugu counterpart. The N-terminal sequence was more variable than the $\mathrm{C}$-terminal sequence of the 
A
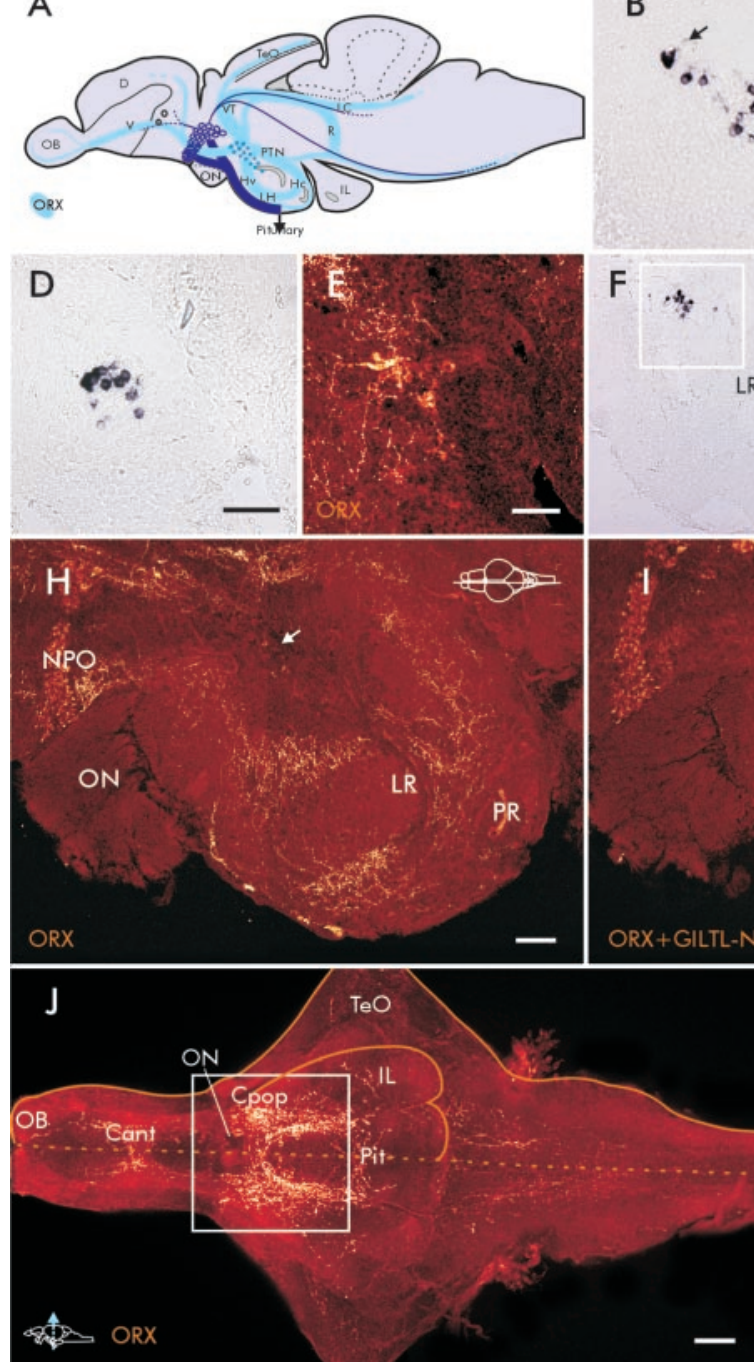
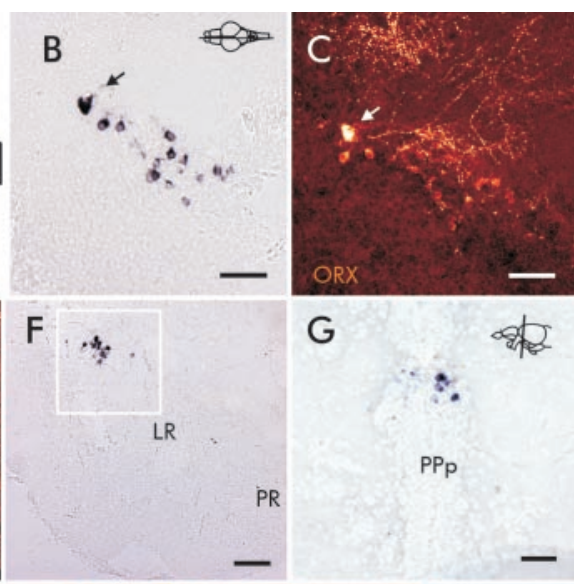
G $\therefore$ $\mathrm{PPp}$
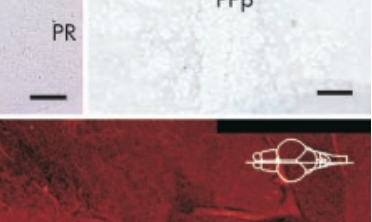

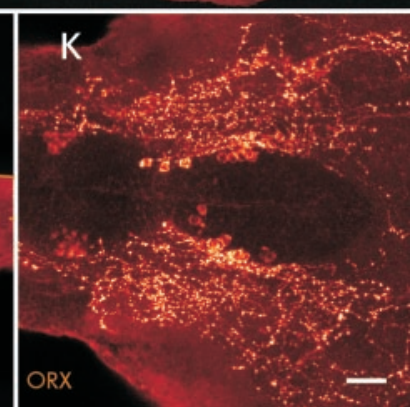

Figure 2. A, A schematic summary drawing of the ORX cell clusters and their widespread projection patterns in the zebrafish brain. The hypothalamic ORX-producing and ORX-containing neurons and their projections are shown in blue, and the preoptic putatively ORX-containing and ORX-producing neurons are shown in dark blue. B, A sagittal view of scattered hypothalamic prepro-ORX mRNA-containing neurons detected with in situ hybridization. C, ORX-IR neurons from a corresponding level stained with an ORX-A antiserum. The arrows in $B$ and C point at the more strongly labeled and slightly larger rostrally situated neuron. $D-F, A$ series of consecutive sagittal sections. $D$ and $F$ show prepro-ORX mRNA-labeled neurons in sections processed with in situ hybridization, whereas $E$ shows neurons stained with $O R X-A$ antiserum. The boxed area in $F$ shows the corresponding area to $D$ and E. G, A coronal section of rostral hypothalamus showing prepro-0RX mRNA-labeled neurons (compare with Fig. 3H-0). H, A sagittal section near the midline of the hypothalamus and neurosecretory preoptic nucleus (NPO) shows a few ORX-IR neurons (arrow). I, A consecutive sagittal section preincubated with the peptide fragment from the C terminal of ORX-A. This peptide blocked immunoreactivity in a concentration-dependent manner. Virtually all immunoreactivity was blocked after preincubation with $1 \mu \mathrm{m}$ GILTL- $\mathrm{NH}_{2}$, except the neurosecretory preoptic nucleus neurons and their characteristic projections toward the pituitary (arrowhead; also see Fig. 5). J, A whole-mount brain preparation of a 10-d-old juvenile zebrafish showing the general organization of the $\mathrm{ORX}$ system from the ventral side. $K$, Higher magnification of the boxed area in $J$ showing the neuronal organization of ORX in the preoptic area and hypothalamus. Scale bars: $B-G, J, 50 \mu \mathrm{m} ; H, I, 100 \mu \mathrm{m} ; K, 25 \mu \mathrm{m}$. Cant, Anterior commissure; Cpop, postoptic commissure; D, dorsal telencephalon; Hv, ventral zone of periventricular hypothalamus; IL, inferior hypothalamic lobe; LH, lateral hypothalamic nucleus; $\mathrm{OB}$, olfactory bulb; $0 \mathrm{~N}$, optic nerve; $\mathrm{PPp}$, parvocellular preoptic nucleus posterior part; Pit, pituitary; $R$, raphe nuclei; Te0, optic tectum; V, ventral telencephalon; VT, ventral thalamus.

zebrafish ORX-B. Only three of the four conserved cysteine residues in the ORX-A peptide were found in the zebrafish and Fugu sequences. These four cysteine residues are predicted to form two intrachain disulfide bonds. Both fish sequences lack the cysteine residue found in position 12 in the human ORX-A sequence (Fig. $1 A)$. However, both fish sequences had an additional cysteine residue in position 19 that was not found in any of the other vertebrate sequences. Furthermore, both the zebrafish and the Fugu ORX-A peptide sequences contained additional amino acids in a region (between residues 24 and 25 in mammals) that is hypothesized as a spacer sequence (Alvarez and Sutcliffe, 2002) and not found in other vertebrates. Although the amino acid sequences of the fish spacer region did not show any significant homology between the two fish species, the location of the region between residues 24 and 25 in mammals was highly conserved.

\section{ORX-containing neurons}

The RT-PCR analysis displayed a clear amplification of prepro-ORX cDNA from the zebrafish forebrain, midbrain (diencephalic parts), heart, and gills (Fig. $1 E$ ). Amplification of $\beta$-actin was evident in all tissues, verifying the integrity and functionality of all cDNA. In addition to the brain, ORX-A immunoreactivity was detected in cells of the gill epithelium and in nerve fibers innervating the heart (data not shown). We did not systematically search for ORX in the peripheral tissue of zebrafish, and other sites of expression remain possible. Expression analysis with oligonucleotide in situ hybridization showed that prepro-ORX mRNAexpressing cells were confined to a restricted region of the preoptic area and the rostral hypothalamus (see Fig. $6 \mathrm{H}$ ). However, the resolution of the autoradiography film did not allow a more exact localization of the mRNA expression, and we therefore performed in situ hybridization with a DIG-labeled prepro-ORX riboprobe. We found a prolonged population of intensely labeled neurons in the rostral hypothalamus. Rostrally, the neurons were situated medially to the medial forebrain bundle, and, more caudally, the neurons were located dorsally above the lateral recessus (LR) and lateral to the posterior tuberal nucleus (PTN). Closer examination revealed that most of the labeled neurons were medium sized $(8-12 \mu \mathrm{m})$ (Fig. $2 B-D)$, and, rostrally, a few intensely labeled neurons slightly larger in size were detected (Fig. $2 B-C$ ).

To study the neuronal ORX system in more detail, we performed immunohistochemistry with antibodies raised against mammalian ORX-A, ORX-B, and preproORX. We were not able to detect any specific staining in the zebrafish brain with the prepro-ORX antiserum (against the $\mathrm{C}$ terminus of mouse prepro-ORX), and this is in accordance with the great differences found between the fish and mammalian prepro-ORX peptide sequences at the $\mathrm{C}$ terminus. The ORX-B antiserum (specific for the $\mathrm{C}$ terminus of human ORX-B) weakly 
detected hypothalamic neurons in a corresponding place to one detected with the colometric ISH, but the intensity was low.

Immunohistochemistry with two antisera against ORX-A detected strongly labeled neurons in the hypothalamus and a widespread network of fibers. The two different antisera against the mammalian ORX-A appeared to stain similar structures in the zebrafish brain but with different sensitivity. The quality of staining and sensitivity of the rabbit ORX-A antisera was superior compared with the goat ORX-A antisera. Consequently, the ORX-A rabbit antiserum was used primarily, and the goat antiserum was only used for double staining with histamine. The special fixative (EDAC) required for double staining with the histamine antiserum compromised the sensitivity of the ORX-A antisera, and, conversely, PFA compromised the sensitivity of the histamine staining. Therefore, additional staining with the rabbit ORX-A antiserum and the rabbit histamine antiserum was performed on consecutive mirror sections. It was possible to distinguish two distinct populations of ORX-immunoreactive (ORXIR) neurons with immunohistochemistry with the ORX-A antisera in the zebrafish forebrain. One separate cluster of ORX-IR neurons was found in the anterior hypothalamus, whereas a second cluster containing several morphologically different neurons was found in the preoptic area. The rabbit ORX-A antisera stained the preoptic cluster more strongly than the goat ORX-A antiserum. We were not able to demonstrate mRNA expression and detection of protein by simultaneous ISH-IHC. However, analysis by ISH and IHC on consecutive mirror sections showed that the hypothalamic ORX-IR neurons were identical to the ones detected by colometric in situ hybridization (Fig. $2 D-F)$. We found little or no overlapping of prepro-ORX mRNA expression and ORX-A immunoreactivity in the neurons detected in the preoptic area. However, the RT-PCR analysis showed a distinct amplification of prepro-ORX cDNA in accurately dissected telencephalic (including preoptic areas) and diencephalic parts (Fig. 1E).

\section{Antiserum specificity}

Considering the relatively low overall homology between the fish and mammalian ORX-A peptides, we wanted to test the specificity of the used antisera. According to the specifications of the manufacturer, the antiserum produced in rabbits was against the full-length bovine ORX-A, whereas the other antiserum produced in goats was against an unknown number of peptides from the $\mathrm{C}$ terminus of human ORX-A. Comparison of the zebrafish and mammalian ORX-A peptide sequences yielded two highly homologous sites, SCRLY and GILTL- $\mathrm{NH}_{2}$, which might function as epitopes for the used antisera. To experimentally test this, the rabbit ORX-A antiserum was preincubated with a concentration series of ORX-A, ORX-B, SCRLY, and GILTL-NH $\mathrm{N}_{2}$. All of the immunostaining was abolished after preincubation with 1-10 $\mu \mathrm{M}$ ORX-A peptide (see Fig. $5 A-F$ ), and the immunostaining was noticeably reduced after preincubation with $0.1 \mu \mathrm{M}$ ORX-A. Even at the highest concentration used $(10 \mu \mathrm{M})$, preincubation with ORX-B or SCRLY peptides did not result in any noticeable blocking of staining (see Fig. 5I,L-P). Preincubation with the GILTL- $\mathrm{NH}_{2}$ peptide abolished most of the staining at the highest concentration $(10 \mu \mathrm{M})$ and markedly reduced the staining at the concentrations 1 and $0.1 \mu \mathrm{M}$ (Fig. 2I) (see Fig. 5Q-V). The preoptic neuronal populations and their thick varicose fibers directed toward the pituitary were still detected after blocking with the GILTL peptide (Fig. 2I) (also see Fig. 5Q-V). Preincubation of the goat ORX-A antiserum with GILTL and ORX-A also blocked the immunostaining in a concentration-dependent manner similar to the rabbit antiserum.

It has been reported that some prolactin antisera cross-react with prepro-ORX and vice versa (Risold et al., 1999). In silico analysis showed that the predicted zebrafish prolactin peptide sequence displayed very low similarity to the mammalian preproORX sequence or mammalian ORX-A. To experimentally test this, additional staining on zebrafish brain sections was done with two different antisera produced against mouse or rat prolactin. None of the two prolactin antisera produced any specific immunoreactivity in the zebrafish brain. Furthermore, no inhibition of staining was detected when the ORX-A antiserum (rabbit) was absorption blocked with synthetic prolactin peptide (recombinant mouse) (see Fig. $5 H, K$ ). These results are in agreement with Risold et al. (1999), because the peptide stretch (fragments 104109 of rat prepro-ORX) recognized as the epitopes for crossreactivity in that study is very different in fish and not present in the peptide sequences used for immunization of the ORX-A antisera.

In conclusion, the blocking experiments showed that the major epitope of the used ORX-A antisera indeed was the C-terminal peptide GILTL- $\mathrm{NH}_{2}$. Furthermore, this is strongly supported by the lacking suppression of immunoreactivity with the ORX-B peptide that has an almost identical peptide sequence (GILTM-NH $\mathrm{N}_{2}$ ). At least one additional epitope except GILTL$\mathrm{NH}_{2}$ was present within the ORX-A peptide sequence for the rabbit ORX-A antiserum, because preadsorption with ORX-A abolished all immunoreactivity, whereas preadsorption with GILTL- $\mathrm{NH}_{2}$ diminished immunoreactivity but did not abolish it completely. This was not surprising, because the antiserum was polyclonal. However, it is still possible that the ORX-A antisera detect other related and so far unidentified peptides in the zebrafish brain in addition to the ORX identified in this study.

\section{ORX-containing neurons and fiber projections}

As a consequence of the previous analyses with RT-PCR, in situ hybridization, and immunohistochemistry, only the hypothalamic cluster can be considered to be truly ORX containing (containing both prepro-ORX mRNA and processed ORX protein), whereas the preoptic neuronal group displays clear immunoreactivity but lacks definite proof of expression of prepro-ORX mRNA.

Two clusters of ORX neurons were distinguished in the zebrafish brain on the basis of morphology and localization with immunohistochemistry (Fig. 2A). A schematic drawing of the major ORX fiber pathways is shown in Figure $2 A$. The majority of the ascending and descending ORX-IR fibers originated from the hypothalamic cluster, whereas the preoptic population predominantly projected to the pituitary (see below).

Multipolar very large-, large-, and small-sized ORXimmunoreactive neurons formed one dense continuous population of neurons in the preoptic area (Figs. $2 H, 3 C, D$ ) (see Fig. $5 G-I)$. This area has been identified and described as the neurosecretory preoptic nucleus in numerous other teleost species ( $\mathrm{Pe}$ ter and Fryer, 1983; Holmqvist and Ekström, 1991). In agreement with this, the large and very large ORX-IR neurons $(12-40 \mu \mathrm{m})$ were found in a dorsal cluster comprising the magnocellular preoptic nuclei and gigantocellular preoptic nuclei (Figs. $2 \mathrm{H}, \mathrm{I}$, $3 A, D$ ) (see Fig. $5 G-I$ ). The small neurons $(6-8 \mu \mathrm{m})$ formed a ventral entity, and they were situated ventrally and slightly rostrally in the posterior parvocellular preoptic nucleus and in the vicinity of the suprachiasmatic nucleus (Fig. $3 F$ ). The preoptic ORX-IR neurons were located caudally and dorsally to the pre- 

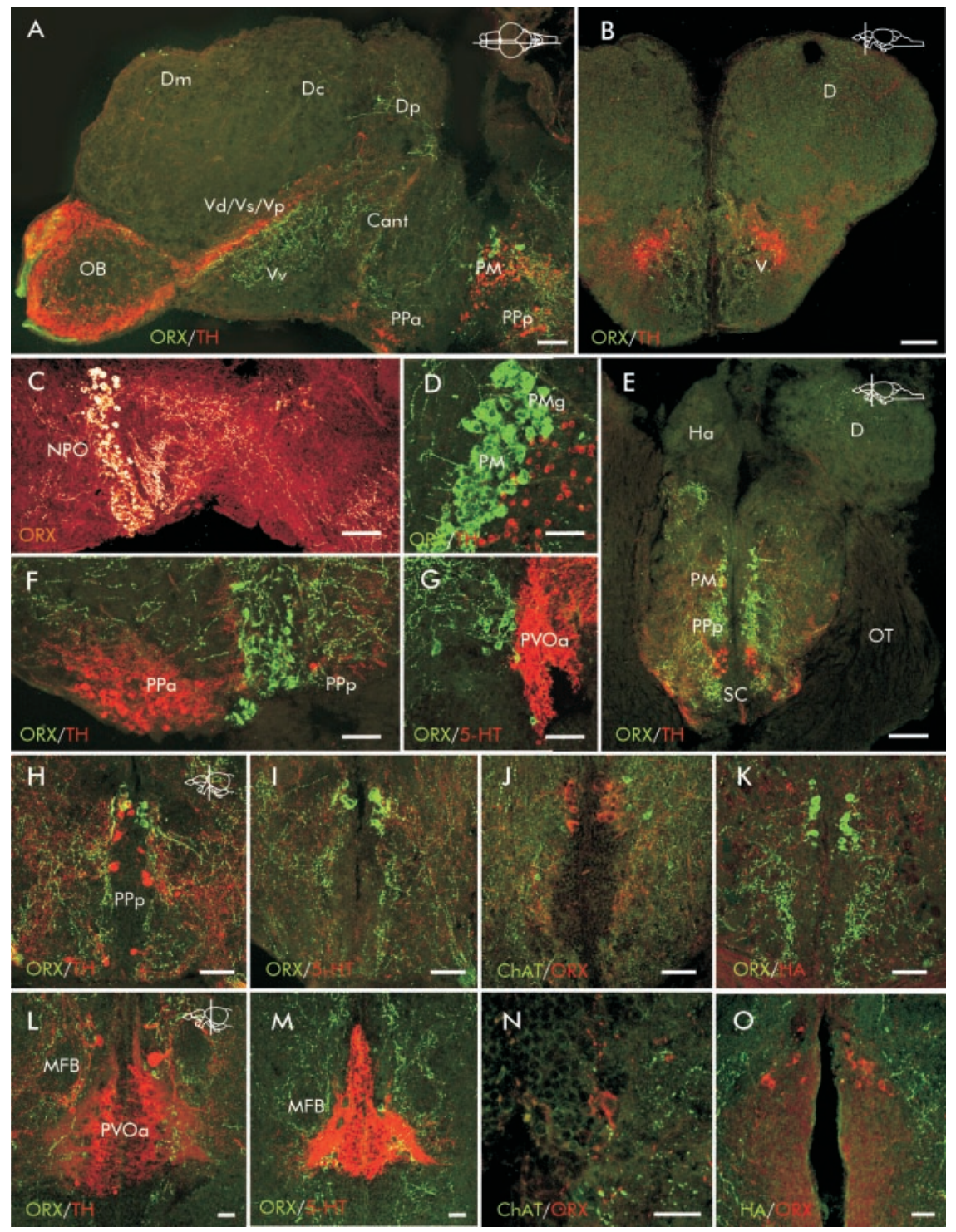

Figure 3. A, A sagittal section of the telencephalon showing ORX neurons in the preoptic area (green) and ascending fibers mostly innervating ventral parts of the telencephalon. The ORX fibers intermingle with the telencephalic and preoptic TH-IR (red) neurons and fibers. $B$, A coronal section from the rostral telencephalon showing ORX fibers (green) ventrally and TH-IR fibers and neurons (red). C, A sagittal section near the midline showing the ORX cell clusters (orange) in the preoptic area and anterior hypothalamus. D, A sagittal section with higher magnification of the large-sized ORX-IR (green) neurons of the magnocellular preoptic nucleus; a column of TH-IR (red) neurons is located caudal to them. E, A coronal section of the rostral preoptic area showing the continuous column of small- and large-sized ORX-IR (green) neurons of the neurosecretory preoptic nucleus (NPO) and the TH-IR neurons (red). F, A sagittal section with higher magnification of the small preoptic rostroventrally situated ORX-IR (green) neurons and, rostrally to them, a cluster of TH-IR (red) neurons. G, A sagittal section with higher magnification showing the hypothalamic ORX-IR neurons (green). They were located outside the periventricular cluster of 5-HT-IR (red) neurons. $H, A$ coronal section of the caudal preoptic area showing large ORX-IR (green) and TH-IR (red) neurons and fibers. I, A coronal section from the same level as in $H$, showing dense 5-HT innervation (red) of the ORX-IR neurons (green). J, A coronal section from the same level as in $H$, showing ChAT-IR innervation (green) of the ORX neurons (red). The preoptic ChAT-IR neurons were always laterally located to the $\mathrm{ORX}$ neurons. $K$, An overlay montage of two-mirror coronal sections from the same level as in $F$, showing histaminergic (HA) fibers (red) in the vicinity of the ORX neurons (green). L, A coronal section from the rostral diencephalon showing the hypothalamic ORX-IR (green) neurons laterally situated to the periventricular cluster of TH-IR (red) neurons. The large TH-IR neurons situated around the medial forebrain bundle (MFB) were densely innervated by $0 \mathrm{RX}$ fibers. $M, A$ coronal section from the same level as in $L$, showing ORX-IR (green) neurons surrounded by a dense network of 5-HT-IR (red) fibers and neurons. $N$, A coronal section from the same level as in L, showing sparse ChAT-IR innervation (green) of an ORX neuron (red). O, A coronal section from the same level as in $L$, showing sparse histaminergic innervation (green) of $0 R X$ neurons (red). Scale bars: $A-C, E, 100$ $\mu \mathrm{m} ; H-K, 50 \mu \mathrm{m} ; L-0,25 \mu \mathrm{m}$. Cant, Anterior commissure; D, dorsal telencephalon; Dc, central zone of dorsal telencephalic area; Dm, medial zone of dorsal telencephalic area; Dp, posterior zone of dorsal telencephalic area; $\mathrm{Ha}$, habenula; $\mathrm{OB}$, olfactory bulb; $0 \mathrm{~T}$, optic tract; $\mathrm{PPa}$, parvocellular preoptic nucleus anterior part; $\mathrm{PPp}$, parvocellular preoptic nucleus posterior part; $\mathrm{PM}$, magnocellular preoptic nucleus; PVOa, paraventricular organ anterior part; SC, suprachiasmatic nucleus; V, ventral telencephalon; Vd, dorsal nucleus of ventral telencephalic area; Vp, posterior nucleus of ventral telencephalic area; $V s$, supracommissural nucleus of ventral telencephalic area; Vv, ventral nucleus of ventral telencephalic area. optic-suprachiasmatic TH-IR neurons (Fig. $3 F, D$ ). Thick fibers with large bulging varicosities emanated from the preoptic neurons, and the vast majority of the fibers were directed toward the pituitary through the preoptic hypophyseal tract (Figs. 2H,I, 3C,E) (see Fig. 5Q-U). The thick varicose ORX-IR fibers in the preoptic hypophyseal tract turned ventrally after the optic tract and followed the ventral surface of the hypothalamus to the pituitary, and TH-IR fibers from preoptic catecholaminergic neurons coursed through the same fiber tract (Fig. 4B). Very few additional descending fibers to the brainstem and ascending fibers to the telencephalon were detected, except the hypophyseal projections (Fig. $2 I, 5 S-V$ ). This is also in agreement with the projection pattern reported for neurons of the neurosecretory preoptic nucleus of other teleosts (Holmqvist and Ekström, 1995). We also counted the number of ORX-IR preoptic neuronal profiles (somata) from a complete series of sagittal $22 \mu \mathrm{m}$ sections of adult zebrafish brains. We found a total of $398 \pm 28$ (mean \pm SEM; $n=5$ ) ORX-IR preoptic neuronal profiles in the adult zebrafish brain. The true number of neurons was most likely lower, because profile counting does not take into account the split somata between adjacent sections and thus inflates the number of profiles counted. We did not try to correct the number with any of the assumption-based correctional methods (Abercrombie, 1946; Coggeshall and Lekan, 1996), because the material as such does not fulfill the requirements of these methods (dense distribution, variable cell size, and irregular cell shape).

A second prolonged cluster of medium-sized $(8-14 \mu \mathrm{m})$ more weakly stained ORX neurons was found in the rostral hypothalamus (Figs. 2, 3G, 4A, B). Most of the ORX-IR neurons were medium sized, and, rostrally, a few more intensely labeled neurons slightly larger in size were detected (Figs. $2 B, C, 3 A, B$ ). Rostrally, the neurons were situated medially to the medial forebrain bundle, and, more caudally, the neurons were located dorsally above the LR and lateral to the PTN. More caudally, they were clearly located outside the clusters of periventricular TH-5-HT-containing neurons (Fig. $3 L, M)$. Furthermore, we counted the number of hypothalamic ORX-IR neuronal profiles (somata) from five complete series of sagittal $22-\mu \mathrm{m}$-thick sections of adult zebrafish brains. We found a total of $43 \pm 5$ (mean \pm SEM; $n=5$ ) ORX-IR neuronal profiles in the zebrafish hypo- 
thalamus. In this case, the number of neurons is likely to be true or very close, because the low number and loose distribution of neurons made it easy to keep track of the origin of the counted profiles. We also counted the hypothalamic ORX-IR neurons in whole-mount brain preparations of 10-d-old juvenile fish. The hypothalamic ORX-IR neurons were readily visible in this type of preparation, and accurate counts could be obtained. We found a total of $9.3 \pm 0.3$ (mean \pm SEM; $n=3$ ) ORX-IR neurons for the left side of the hypothalamus and a mean \pm SEM of $10 \pm 0.6$ ORX-IR neurons for the right side of the hypothalamus, which gives a total of $\sim 20$ hypothalamic ORX-IR neurons at this time point.

The ascending ORX-IR fibers moderately innervated the ventromedial telencephalic area, and a minor part continued in to the olfactory bulb, which was sparsely innervated throughout all layers except the most external layer (Fig. $3 A, B$ ). Some of the fibers crossed the anterior commissure. The majority of the ORX-IR fibers were clearly located ventral to the telencephalic dopaminergic cells and fibers. The caudal lateral and dorsal telencephalic areas received scarce fibers, whereas the rostrodorsal parts were almost devoid of ORX-IR fibers.

The majority of the ORX-IR fiber projections were descending, and they projected through the ventromedial hypothalamus or through the dorsal diencephalic areas. Two main ventrally descending pathways could be distinguished, a ventral preoptic hypophyseal tract originating from the preoptic neurons and a second ventromedial one originating from the hypothalamic neurons that innervated the ventral hypothalamic areas (Figs. $2 H, J, K$, $4 A, B)$. The ventromedial fiber bundle followed the lateral margin of the ventral periventricular hypothalamus and innervated ventral, lateral, and caudal hypothalamic nuclei, including the lateral hypothalamic nucleus and the caudal zone of the periventricular hypothalamus (Hc). The anterior tuberal nucleus was almost devoid of ORX-IR fibers (Figs. $2 H, J, K, 4 A, B$ ).

Two dorsally descending fiber pathways were identified, one that followed the tectal roof laterally and another that followed the tuberal nuclei medially (Figs. $2 K, 4 A, B$ ). The ORX-IR fibers that followed the dorsomedial pathway innervated medial areas around the PTN and the lateral part of the periventricular nucleus of the posterior tuberculum (Figs. $3 L, M, 4 A, B$ ). More caudally, some fibers turned ventrally and innervated the caudal zone of the periventricular hypothalamus $(\mathrm{Hc})$, and others continued into the raphe (Figs. $2 J, 4 B, H, 6 B, C$ ). The descending dorsolateral bundle densely innervated the thalamic nuclei, including the anterior, intermediate, ventromedial, and ventrolat-
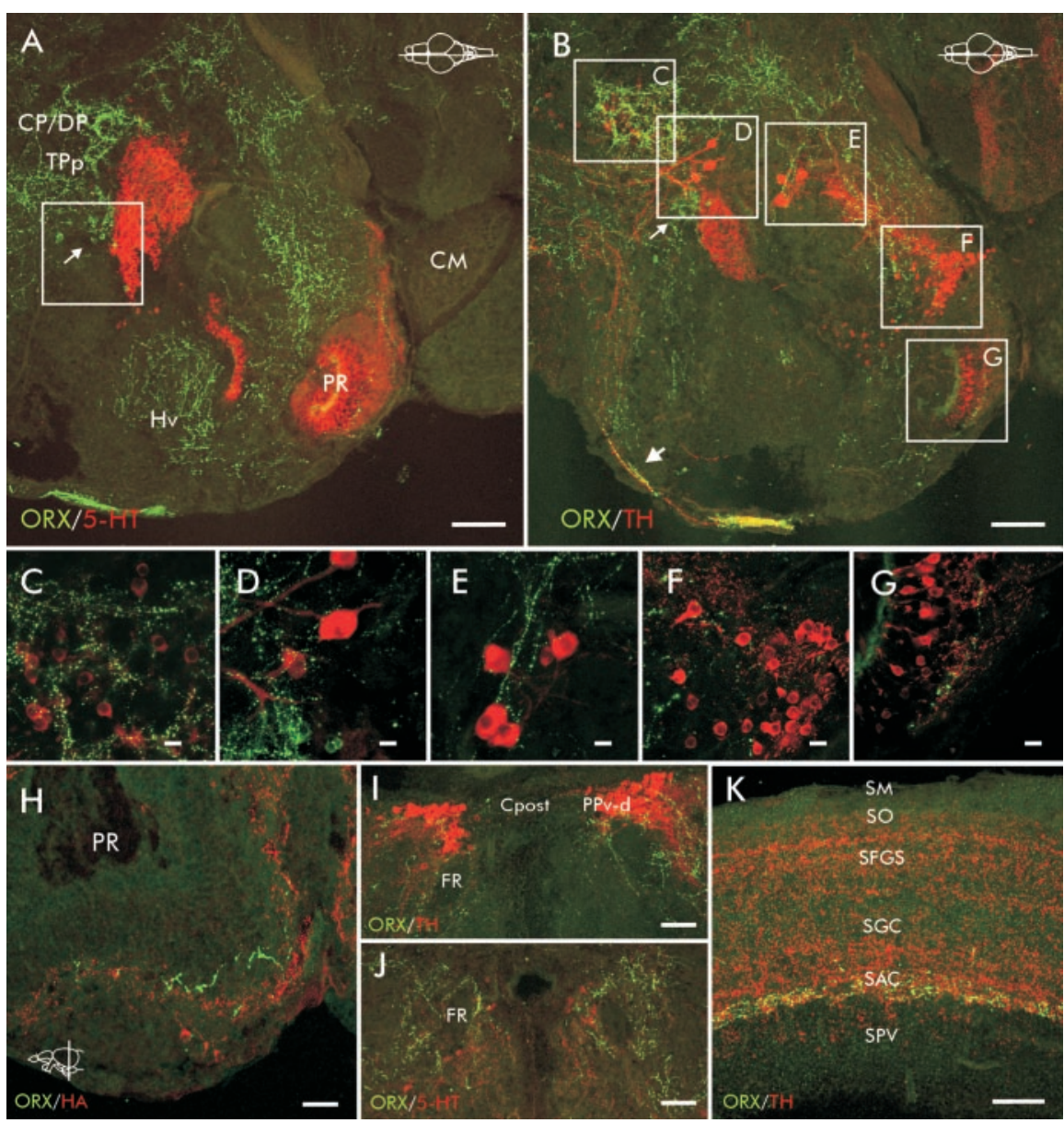

Figure 4. A, A midsagittal section of the ventral diencephalon showing ORX-IR neurons (green, arrowhead) and their very widespread fiber projections. The paraventricular serotonergic neurons (red) were found caudal to the ORX-IR neurons. The framed area in $A$ is shown in high magnification in Figure 3G. $B$, Another midsagittal section showing the ORX-IR (green) neurons (arrowhead) and fibers and their contribution to the diencephalic catecholaminergic clusters (red). The preoptic hypophyseal tract the framed areas are shown in C-G.C, High-magnification image of TH-IR (red) neurons in the periventricular nucleus of posterior tuberculum (TPp) and dense input from ORX-IR fibers (green). D, E, High-magnification images showing the large diencephalic input to the TH-IR (red) neurons of the dorsocaudal hypothalamus. G, High magnification of the ventrocaudal hypothalamus. ORX-IR fibers (green) were always found outside the periventricular TH-IR (red) neurons lining the PR. H, An overlay image of two . ORX (green) fibers and TH-IR (red) neurons in the periventricular pretectum. J, A coronal section showing ORX (green) fibers and (he pretectum. $K$, A coronal section through the optic tectum (Te0) showing ORX (green) fibers restricted H-K, $50 \mu \mathrm{m}$. CM, Mammillary corpus; $C \mathrm{P}$, central posterior thalamic nucleus; Cpost, posterior commissure; DP, dorsa pretectal nucleus dorsal part; PPv, periventricular pretectal nucleus ventral part; SFGS, stratum fibrosum et griseum superficiale; SGC, stratum griseum centrale; SM, stratum marginale; SO, stratum opticum; SPV, stratum periventricular.

eral thalamic nuclei (Fig. $3 A, E, I, J)$. The dorsal thalamic nuclei were sparsely to intermediately innervated (Fig. $4 A, B$ ). Some pretectal nuclei, such as the periventricular pretectal nuclei $(\mathrm{PPv})$, were highly innervated, and a few fibers crossed the posterior commissura (Fig. 4I,J). Pretectal nuclei, including the dopa decarboxylase-TH-5-HT-IR neurons in the PPv, were densely innervated by ORX-IR fibers (Fig. 3I,J). Some fibers distinctly innervated the optic tectum dorsocaudally to the thalamic nuclei. In the optic tectum, ORX-IR fibers were found as a dense band restricted to the stratum griseum centrale and stratum album centrale (Fig. $4 K$ ). Descending fibers followed and innervated lateral nuclei of the dorsal tectum and tegmentum 

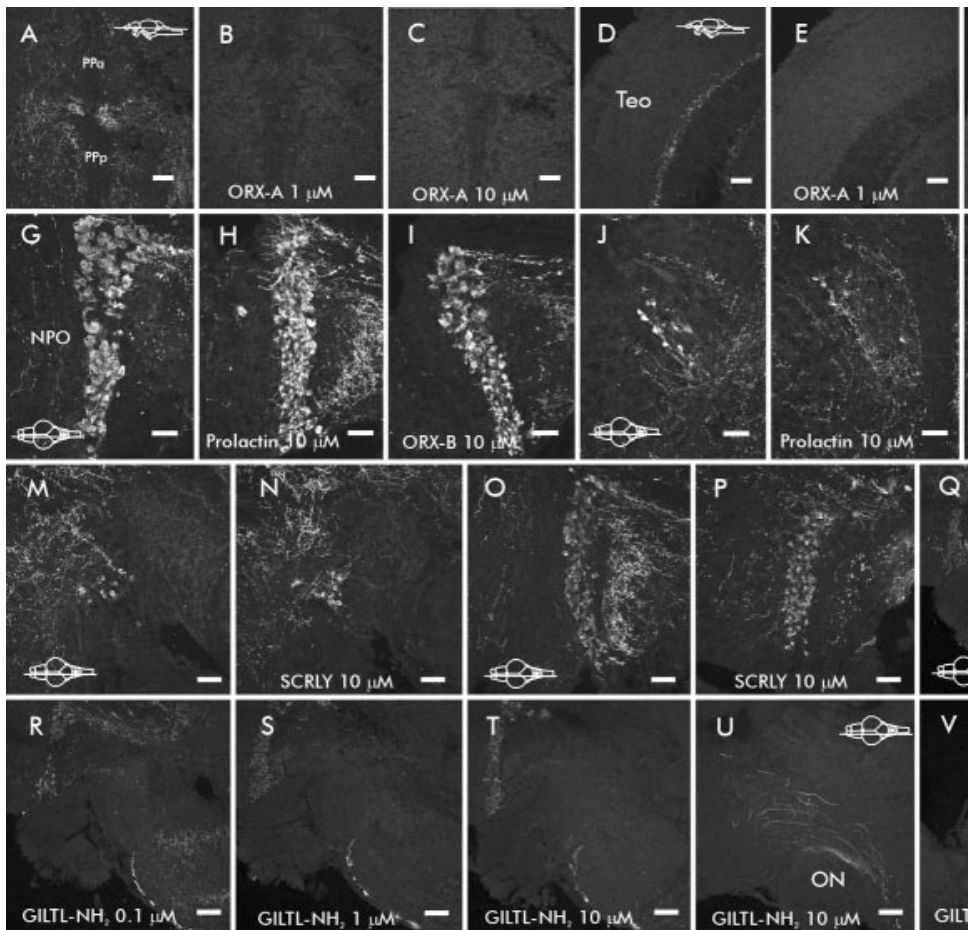

Figure 5. Specificity controls were done by preincubations of the ORX-A antiserum with ORX-A, ORX-B, prolactin, SCRLY, and GILTL-NH 2 peptides. $A-F$, A series of horizontal sections preincubated with ORX-A. $A$, A horizontal section at the level of the preoptic area and rostral hypothalamus showing ORX-IR neurons. $B, C$, No immunoreactivity was detected after preincubation with ORX-A (1-10 $\mu \mathrm{M})$. D, A horizontal section showing ORX-IR in the optic tectum (Te0). E, F, The ORX-ir fibers were absent after preincubation with ORX-A. G-P, Sagittal sections showing the ORX-IR neurons in the preoptic area and the hypothalamus. Preadsorption of the ORX-A antiserum with prolactin, ORX-B, and SCRLY (10 $\mu \mathrm{m})$ did not affect the immunoreactivity of the ORX-IR neurons or fibers. $Q-T$, Sagittal sections showing $O R X-I R$ neurons and fibers in the diencephalon. The immunoreactivity diminished in a concentration-dependent manner after preincubating the ORX-A antiserum with the ORX-A fragment GILTL-NH 2 . No or very little immunoreactivity was detected after preadsorption with $10 \mu \mathrm{m}$ peptide, except neurons of the preoptic area and their characteristic projections. U, A sagittal section showing unblocked thick varicose fibers from the preoptic neurons. $V$, No immunoreactivity was seen in the optic tectum after preadsorption with the peptide fragment. Scale bars: $A-P, 50 \mu \mathrm{m} ; Q-V, 100 \mu \mathrm{m}$. NPO, Neurosecretory preoptic nucleus; PPa, parvocellular preoptic nucleus anterior part; PPp, parvocellular preoptic nucleus posterior part.

more caudally in the diencephalon. The outer margin of both the ventrolateral part of the torus semicircularis and the central nucleus of torus semicircularis were densely to moderately innervated by ORX-IR fibers (Fig. 6A, B). More caudally, the ORX-IR fibers turned medially innervated the dorsal tegmentum, including the griseum centrale, locus ceruleus (LC), and especially the serotonergic raphe (Fig. 6C,D). The central gray was innervated by ORX-IR fibers through its whole length. ORX-IR fibers caudal to the tegmentum sparsely innervated the ventral and medial parts of the medulla (Fig. $2 J$ ).

\section{Cholinergic (ChAT-IR) neurons}

The cholinergic system in the zebrafish brain has not been described previously. It is not clear whether all ChAT-expressing neurons in fish are truly cholinergic (release of acetylcholine as a neurotransmitter). Therefore, we refer to them as ChAT immunopositive rather than cholinergic cells. The emphasis was on the identification of telencephalic and tegmental cholinergic clusters that might correspond to the mammalian cholinergic basal forebrain and mesopontine system. The other cholinergic clusters are mentioned only briefly here, and a more detailed characterization of the organization of the cholinergic system will be presented in the future. In the telencephalon, a few small ChAT-IR neurons were found in the central and dorsal nucleus of the ventral telen-
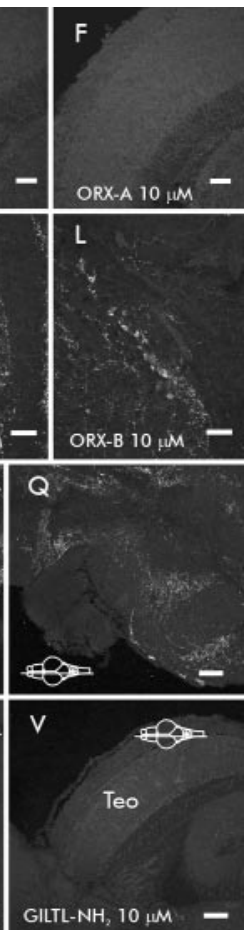

cephalic area. In the diencephalon, ChAT-IR neurons were found in the preoptic area, dorsal thalamus, pretectal nuclei, and hypothalamus (data not shown). In the mesencephalon and rhombencephalon, ChAT-IR neurons were found in the optic tectum, tegmentum, reticular formation, and in association with the cranial and spinal nerve motor nuclei NIII-NX, LX (data not shown). Several clusters of ChAT-IR neurons were found in the dorsal tegmental area. Except the easily distinguishable motor nuclei-associated ChAT-IR clusters, at least four major clusters were found on the basis of distribution and morphology. A large intermingling complex of small ovoid ChAT-IR neurons was found from the oculomotor nucleus rostrally to the secondary gustatory nucleus (SGN) caudally. This complex could approximately be divided into three clusters on the basis of their immunoreactivity and localization. The most rostral of these clusters was located dorsolateral to the lateral longitudinal fascicle (LLF), and the neurons followed the outline of the perilemniscal nucleus throughout its whole length (Fig. 6A). A second slightly more caudal cluster with intense immunoreactivity was located in the nucleus lateralis valvula (NLV), and this cluster partly followed the outline of the NLV and the SGN to the commissure of the secondary gustatory nuclei in caudal direction (Fig. 6A,B). A third cluster with medium immunoreactivity was found laterally to the NLVSGN complex in the nucleus isthmi. A fourth cluster of ChAT-IR neurons with a distinct morphology different from the other isthmic neurons was found at the level of the trochlear nucleus. This cluster contained intensely immunoreactive, largesized multipolar neurons (Fig. 6B).

\section{ORX input to the cholinergic and aminergic systems}

In the telencephalon and olfactory bulbs, the ORX fiber input to the aminergic or ChAT-IR systems was scarce. ORX fibers occasionally intermingled with the TH-IR neurons, and fibers found in the vicinity of the medial olfactory tract and putative contacts between the two systems were only seen rarely (Fig. $3 A, B$ ). In the preoptic area, the most rostral catecholaminergic neurons in parvocellular preoptic nucleus anterior part did not receive any ORX input, whereas the ones more caudally and dorsally in the vicinity of the magnocellular ORX neurons were scarcely to moderately innervated as well as the anterior thalamic catecholaminergic neurons (Fig. 3D, H). The preoptic ChAT-IR neurons were moderately innervated by ORX fibers (Fig. 3J). ORX fibers innervated pretectal nuclei in which catecholaminergic, serotonergic, and ChAT-IR clusters are located. Contacts with both the serotonergic and catecholaminergic neurons could be detected (Fig. 4I,J).

The anterior thalamic and tuberal catcholaminergic neurons received moderate to dense fiber innervation, and putative contacts could be detected at several instances (Fig. $4 B, C$ ). The tectal and diencephalic ChAT-IR neurons received scarce or no input 
from ORX fibers. The hypothalamic ORX neurons were found laterally very close to the serotonergic and catecholaminergc clusters, and, in this area, the ORX neurons were surrounded by the thin processes that emanated from the paraventricular aminergic neurons (Figs. $3 L, M$, $4 A, B)$. Putative contacts were detected on the soma and dendrites of the large-sized catecholaminergic neurons (Fig. $4 B, D, E$ ). The catecholaminergic cluster dorsal to the posterior recess of diencephalic ventricle $(\mathrm{PR})$ received moderate to dense ORX fiber input, and a few putative contacts were detected (Fig. 4B,F). Ventral to this location, ORX fibers innervated areas around the PR, in which several clusters of aminergic neurons were located (Fig. $4 A, B)$. ORX-IR fibers were very seldom detected among the periventricular aminergic neurons (5-HT-TH-IR) that were lining the recessus (Fig. $4 A, B, G$ ). The ORX fibers were seen in outer layers, in which the histaminergic neurons are found. It was not possible to detect contacts between ORX fibers and histaminergic neurons, because double staining with the two markers failed. However, analysis with consecutive mirror sections indicated close contacts (Fig. $4 H$ ).

The tegmental area was one of the major innervation fields of the ORX fibers. Numerous contacts between ORX-IR axons and serotonergic neurons and dendrites were detected in both medial and dorsal raphe (Fig. $6 C, G)$. Contacts between ORX fibers and the noradrenergic neurons of the LC were also found (Fig. 6D, F). However, these contacts were much fewer than those with the raphe nuclei. Although the dorsal tegmentum received dense ORX innervation, very few ChAT-IR neurons received ORX input (Fig. $6 A$ ). The large-sized ChAT-IR neurons medial to the LLF and some areas of the ChAT-IR NLV received sparse ORX fiber innervation (Fig. 6B,E). The ORX input to the medullary region was modest altogether, and little input to the caudal aminergic systems and the ChAT-IR neurons of the caudal reticular formation was detected.

\section{Cholinergic and aminergic input to the ORX system}

The preoptic ORX-IR clusters were innervated by serotonergic, catecholaminergic, histaminergic, and cholinergic fibers. Catecholaminergic fibers densely innervated the parvocellular part of the ORX-IR cluster, whereas the serotonergic fibers densely innervated both the magnocellullar and parvocellular clusters (Fig. 3D-F,H,I). Several contacts between the catecholaminergic and serotonergic fibers and the ORX neurons and dendrites were detected (Fig. $3 H, I$ ). Histaminergic fibers seemed to innervate both preoptic ORX clusters. It was not possible to double label the specimens for histamine and ORX simultaneously. However, analysis with consecutive mirror sections indicated
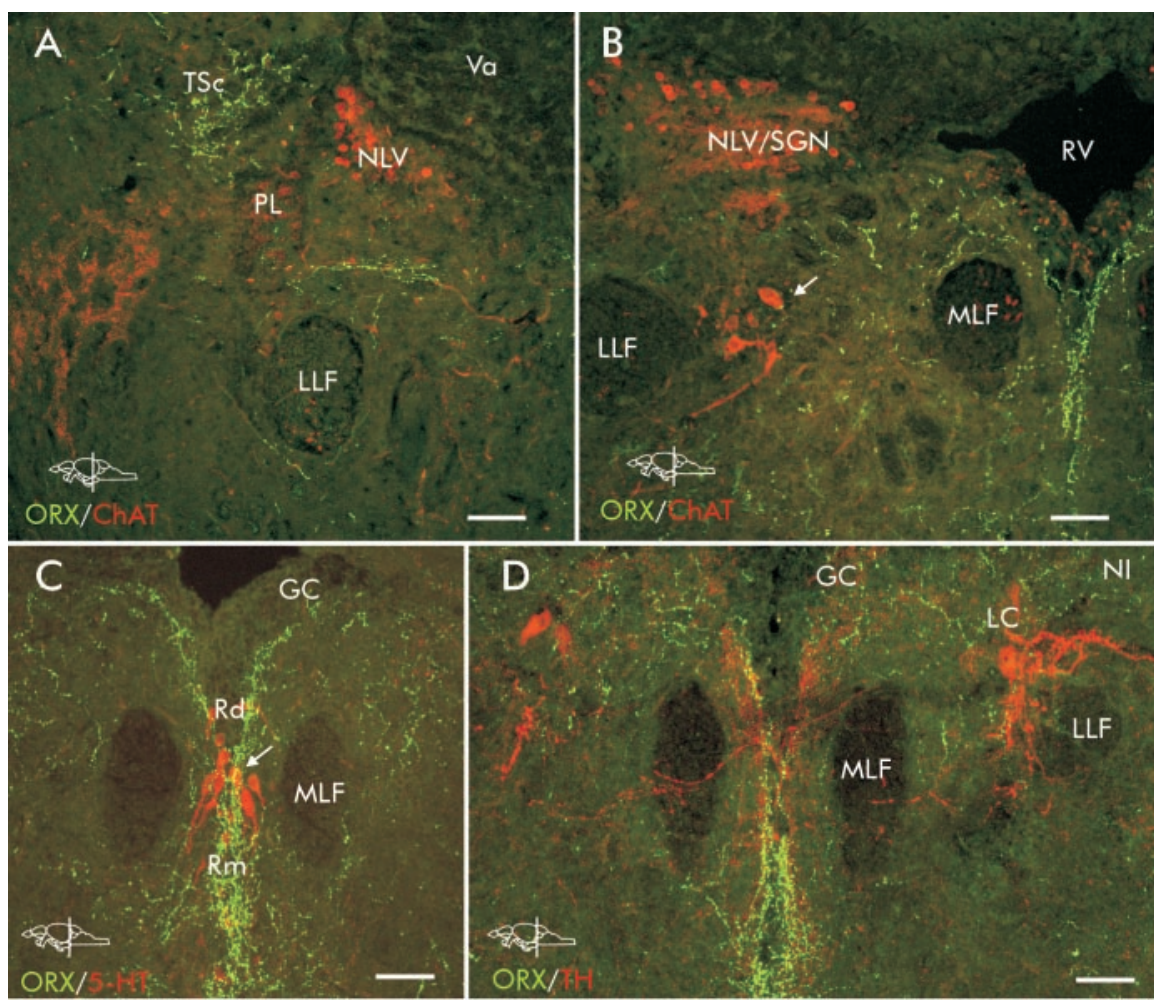

NI (red), and ORX-IR fibers (green). $B$, A slightly more caudal coronal section showing small- and large-sized ChAT-IR neurons (red) and ORX fibers (green). The large-sized ChAT-IR neurons are proposed to be similar to the mesopontine ChAT-IR neurons in and dendrites (red). D, A slightly more caudal coronal section showing dense ORX innervation (green) through the raphe and to ( of unlabeled probes and sections labeled (right column) with a probe designed to recognize the spacer region of the prepro-0RX mRNA. Specific binding was detected only in the anterior hypothalamus and the preoptic area (arrow). However, the resolution of the autoradiography film did not allow a more exact localization. Scale bars: $A-D, 50 \mu \mathrm{m} ; E-G, 10 \mu \mathrm{m}$. GC, Central gray; MFB, medial forebrain bundle; Rd, dorsal raphe nucleus; Rm, medial raphe nucleus; Rv, rhombencephalic ventricle; TSc, central nucleus of semicircular torus; Va, valvula cerebelli.

close contacts (Fig. $3 \mathrm{~K}$ ). Sparse to moderate ChAT-IR innervation of both of the preoptic ORX clusters as well as a few contacts was detected (Fig. 3J).

The hypothalamic ORX cluster was surrounded by a network of thin processes emanating from the paraventricular aminergic neurons (Fig. 4A,B). However, no clear contacts to the ORX neurons or dendrites were detected (Figs. $3 G, L, M, 4 E$ ). The hypothalamic ORX neurons were sparsely innervated by histaminergic and ChAT-IR fibers, and only a few putative contacts were detected (Fig. 4N,O).

\section{Discussion}

The structure of the zebrafish ORX peptides showed a high degree of homology with the other vertebrate ORX peptides (Saku- 
rai et al., 1998; Shibahara et al., 1999; Alvarez and Sutcliffe, 2002; Ohkubo et al., 2002). Overall, the sequence of the ORX-A is less conserved than the ORX-B peptide sequences in vertebrates. The zebrafish ORXs show the highest homology to the Fugu peptides and an equal homology to other vertebrate sequences. The fish sequences deviate from the other vertebrate sequences by lacking one of the four conserved cysteine residues in the ORX-A peptide. These cysteine residues are predicted to form two intrachain disulfide bonds. However, both fish sequences contain an additional cysteine residue, and, consequently, the double intrachain disulfide topology of the peptide might still be conserved. The fish ORX-A peptide sequences contain a spacer region not found in other vertebrates. The conserved feature of this region in fish and the absence of significant homology in this region between the two fish species further strengthen the hypothesis (Alvarez and Sutcliffe, 2002) that implies that this region is structurally nonfunctional and thus only serves as a spacer region.

In the zebrafish, one hypothalamic ORX-containing cluster was present (containing both prepro-ORX mRNA and ORX protein), whereas another putatively ORX-containing cluster was found in the preoptic area. Naturally, this leads to an inquiry about the true nature of the preoptic neurons. The lack of detected prepro-ORX mRNA with ISH and clear detection with RT-PCR might be a sensitivity issue, and the preoptic neurons thus would produce small amounts of prepro-ORX mRNA. However, the preoptic neurons were readily detected with immunohistochemistry against mammalian ORX-A, and this would not suggest low expression of prepro-ORX mRNA. The preadsorption experiments showed that the epitopes detected with the ORX-A antisera were within the mammalian ORX-A peptide and that the main epitope was the C-terminal sequence GILTL- $\mathrm{NH}_{2}$. Intriguingly, at least one additional epitope was present and specifically labeled in the preoptic neurons. Whether this epitope is present in the zebrafish ORX-like peptide or whether the antisera detect another structurally related and so far unidentified peptide remains unclear. Intriguingly, the ORX-containing neurons in amphibians detected with ORX-A and ORX-B antisera (Shibahara et al., 1999; Galas et al., 2001) were found in corresponding preoptic and hypothalamic areas in zebrafish. The ORX neurons in chicks were found in a continuous cluster mainly in two hypothalamic areas, the periventricular hypothalamic nucleus and the lateral hypothalamic area (Ohkubo et al., 2002). The ORX cluster in chicks might be equivalent to both preoptic and hypothalamic or only the hypothalamic cluster of fish and amphibians. In mammals, the ORX neurons are localized in the perifornical and lateral hypothalamic area (de Lecea et al., 1998; Peyron et al., 1998; Chemelli et al., 1999; Thannickal et al., 2000). Although the organization of ORX neurons in mammals often is described as homogenous and well confined, the distribution of ORX neurons in rodents is scattered (Eriksson et al., 2001). Furthermore, there are several indications of heterogeneity among the mammalian ORX neurons (Beuckmann and Yanagisawa, 2002). On the basis of these findings, it is possible to conclude that a hypothalamic localization of ORX neurons is phylogenetically well preserved, although the putative preoptic localization might be a fish- and amphibian-specific feature so far unidentified in mammals.

Although there are differences in the neuronal organization between fish and mammals, the major projection patterns of ORX fibers were surprisingly similar. In zebrafish, the majority of ORX fibers in the forebrain were found in subpallial areas that are proposed to be homologous to striatoseptal areas of land vertebrates, although the dorsal forebrain area was almost devoid of fibers. In mammals and frogs, subpallial areas were highly inner- vated by ORX fibers, whereas the cortex received fewer fibers (Peyron et al., 1998; Galas et al., 2001). ORX fibers densely innervated the optic tectum and the torus semicircularis in zebrafish, areas known as multisensory integration centers. In mammals, the hypothalamic arcuate and periventricular nuclei are highly innervated by ORX fibers, and similar areas are highly innervated in zebrafish. The abundant projections toward the pituitary from preoptic ORX neurons in fish and frogs suggest a significant involvement of ORX in regulation of secretion of pituitary hormones. Similarly, ORX controls the secretion of hormones from the pituitary in mammals (van den Pol et al., 1998; Russell et al., 2001). In zebrafish, high densities of ORX fibers were found in hypothalamic nuclei that may be involved in regulation of energy homeostasis in fish. ORX fibers densely innervated and contacted several diencephalic catecholaminergic clusters in zebrafish; similarly, there are abundant ORX fibers in hypothalamic nuclei and midbrain structures in mammals (Peyron et al., 1998). These clusters are all considered to be dopaminergic, because the only identified noradrenergic neurons are located in the tegmentum and medulla (Ma, 1994a,b; Kaslin and Panula, 2001). Some of these clusters have been proposed to be similar to the mammalian ascending dopaminergic system (ventral tegmental area and substantia nigra), whereas others are proposed to belong to the descending dopaminergic system (Kaslin and Panula, 2001; Rink and Wullimann, 2001). There are very few studies on the ORX input to dopaminergic neurons in mammals (Korotkova et al., 2003).

ORX fibers densely innervated several previously identified clusters of aminergic neurons in the zebrafish brain (Kaslin and Panula, 2001). This is in agreement with studies in mammals in which the ORX system densely innervates aminergic nuclei (Peyron et al., 1998). The aminergic and cholinergic neurons in mammals express both ORX receptors (Marcus et al., 2001), and electrophysiological studies have shown that the aminergic and cholinergic neurons are excited by ORX (Horvath et al., 1999; Eggermann et al., 2001; Eriksson et al., 2001; Brown et al., 2002; Korotkova et al., 2003).

We showed previously that the aminergic fibers densely innervate preoptic and hypothalamic nuclei in the zebrafish brain (Kaslin and Panula, 2001). Aminergic and ChAT-IR input to the preoptic ORX clusters was more abundant than it was to the hypothalamic cluster. Putative contacts were detected between these systems and the ORX system, indicating a reciprocal relationship. Aminergic and cholinergic inputs to ORX neurons have been proposed in mammals but not shown, except for histamine (Eriksson et al., 2001). However, it was shown recently that noradrenaline and serotonin had an inhibitory effect on ORX neurons, whereas histamine and acetylcholine showed little effect ( $\mathrm{Li}$ et al., 2002). The histaminergic neurons in the zebrafish brain are distributed in a single cluster confined to the ventrocaudal hypothalamus (Kaslin and Panula, 2001). The thin bundle of ORX fibers that innervated this limited area seemed to target the histaminergic neurons, because the ORX fibers were never found among the aminergic periventricular neurons. Reciprocal contacts between the systems have been reported in mammals (Eriksson et al., 2001; Yamanaka et al., 2002). The tegmental area, including ChAT-IR, noradrenergic, and serotonergic clusters, was one of the most densely ORX-innervated areas in the zebrafish brain. ORX fibers heavily innervated both dorsal and medial parts of the serotonergic raphe, and contacts between ORX fibers and serotonergic dendrites and somas were abundant. The density of ORX fibers in the zebrafish LC was much lower than in the raphe. However, the total number of noradrenergic neurons in 
the zebrafish LC is very low (6-20) (Ma, 1994a,b). ORX fibers made contacts with the noradrenergic dendrites in zebrafish; similarly, contacts between ORX fibers and noradrenergic neurons were detected in mammals (Horvath et al., 1999). The tegmental ChAT-IR clusters in zebrafish received little to intermediate ORX input, and few contacts were detected. Only the large ChAT-IR neurons of the mesopontine-like cluster and some of the neurons in the NLV received ORX fibers. In mammals, the parabigeminal nucleus contained few ORX fibers, whereas the mesopontine clusters received intermediate input (Peyron et al., 1998).

It is known that the ORX system, the aminergic systems, and the cholinergic system are involved in the regulation of sleep and vigilance in mammals. There are abundant interactions between these neurotransmitters, and their interplay is thought to be essential in the control of these behaviors (Mignot et al., 2002; Pace-Schott and Hobson, 2002). Sleep or a state of rest is a fundamental biological process that is phylogenetically well conserved (Hendricks et al., 2000; Greenspan et al., 2001). Although some components of sleep are well preserved, it is not known whether sleep as such is comparable between animals (Panda et al., 2002). However, zebrafish display a sleep-like state that is controlled by homeostatic mechanisms and circadian rhythms (Whitmore et al., 1998; Zhdanova et al., 2001; Cahill, 2002).

The organization of the ORX system of the zebrafish resembled that of other vertebrates, including a widespread fiber system and input to the aminergic and ChAT-IR cell groups. Furthermore, we detected input from these systems to the ORX system, and, thus, a reciprocal relationship exists in zebrafish that functionally may be important. These results suggest that these neurotransmitter systems in zebrafish may be involved in regulation of states of wakefulness and energy homeostasis by similar mechanisms as those in mammals.

\section{References}

Abercrombie M (1946) Estimation of nuclear population from microtome sections. Anat Rec 94:239-247.

Alvarez CE, Sutcliffe JG (2002) Hypocretin is an early member of the incretin gene family. Neurosci Lett 324:169-172.

Balter M (1995) In Toulouse, the weather and the science are hot. Science 1269:480-481.

Beuckmann CT, Yanagisawa M (2002) Orexins: from neuropeptides to energy homeostasis and sleep/wake regulation. J Mol Med 80:329-342.

Brown RE, Sergeeva OA, Eriksson KS, Haas HL (2002) Convergent excitation of dorsal raphe serotonin neurons by multiple arousal systems (orexin/hypocretin, histamine, and noradrenaline). J Neurosci 22:8850-8859.

Cahill GM (2002) Clock mechanisms in zebrafish. Cell Tissue Res 309:2734.

Chemelli RM, Willie JT, Sinton CM, Elmquist JK, Scammell T, Lee C, Richardson JA, Williams SC, Xiong Y, Kisanuki Y, Fitch TE, Nakazato M, Hammer RE, Saper CB, Yanagisawa M (1999) Narcolepsy in orexin knockout mice: molecular genetics of sleep regulation. Cell 98:437-451.

Coggeshall RE, Lekan HA (1996) Methods for determining numbers of cells and synapses: a case for more uniform standards of review. J Comp Neurol 364:6-15.

de Lecea L, Kilduff TS, Peyron C, Gao X, Foye PE, Danielson PE, Fukuhara C, Battenberg EL, Gautvik VT, Bartlett II FS, Frankel WN, van den Pol AN, Bloom FE, Gautvik KM, Sutcliffe JG (1998) The hypocretins: hypothalamus-specific peptides with neuroexcitatory activity. Proc Natl Acad Sci USA 95:322-327.

Dooley K, Zon LI (2000) Zebrafish: a model system for the study of human disease. Curr Opin Genet Dev 10:252-256.

Eggermann E, Serafin M, Bayer L, Machard D, Saint-Mleux B, Jones BE, Muhlethaler M (2001) Orexins/hypocretins excite basal forebrain cholinergic neurones. Neuroscience 108:177-181.

Eriksson KS, Sergeeva O, Brown RE, Haas HL (2001) Orexin/hypocretin excites the histaminergic neurons of the tuberomammillary nucleus. J Neurosci 21:9273-9279.

Fishman MC (2001) Genomics. Zebrafish: the canonical vertebrate. Science 294:1290-1291.

Galas L, Vaudry H, Braun B, van den Pol AN, de Lecea L, Sutcliffe JG, Chartrel N (2001) Immunohistochemical localization and biochemical characterization of hypocretin/orexin-related peptides in the central nervous system of the frog Rana ridibunda. J Comp Neurol 429:242-252.

Greenspan RJ, Tononi G, Cirelli C, Shaw PJ (2001) Sleep and the fruit fly. Trends Neurosci 3:142-145.

Haffter P, Granato M, Brand M, Mullins MC, Hammerschmidt M, Kane DA, Odenthal J, van Eeden FJ, Jiang YJ, Heisenberg CP, Kelsh RN, FurutaniSeiki M, Vogelsang E, Beuchle D, Schach U, Fabian C, Nusslein-Volhard C (1996) The identification of genes with unique and essential functions in the developement of the zebrafish, Danio rerio. Development 123:1-36.

Hendricks JC, Sehgal A, Pack AI (2000) The need for a simple animal model to understand sleep. Prog Neurobiol 4:339-351.

Holmqvist BI, Ekström P (1991) Galanin-like immunoreactivity in the brain of teleosts: distribution and relation to substance $\mathrm{P}$, vasotocin, and isotocin in the Atlantic salmon (Salmo salar). J Comp Neurol 306:361-381.

Holmqvist BI, Ekström P (1995) Hypophysiotrophic systems in the brain of the Atlantic salmon. Neuronal innervation of the pituitary and the origin of pituitary dopamine and nonapeptides identified by means of combined carbocyanine tract tracing and immunocytochemistry. J Chem Neuroanat 8:125-145.

Horvath TL, Peyron C, Diano S, Ivanov A, Aston-Jones G, KilduffTS, van den Pol AN (1999) Hypocretin (orexin) activation and synaptic innervation of the locus coeruleus noradrenergic system. J Comp Neurol 415:145-159.

Kaslin J, Panula P (2001) Comparative anatomy of the histaminergic and other aminergic systems in zebrafish (Danio rerio). J Comp Neurol 440:342-377.

Kilduff TS, Peyron C (2000) The hypocretin/orexin ligand-receptor system: implications for sleep and sleep disorders. Trends Neurosci 23:359-365.

Korotkova TM, Sergeeva OA, Eriksson KS, Haas HL, Brown RE (2003) Excitation of ventral tegmental area dopaminergic and nondopaminergic neurons by orexins/hypocretins. J Neurosci 23:7-11.

Li Y, Gao XB, Sakurai T, van den Pol AN (2002) Hypocretin/orexin excites hypocretin neurons via a local glutamate neuron-A potential mechanism for orchestrating the hypothalamic arousal system. Neuron 36:1169-1181.

Ma P (1994a) Catecholaminergic systems in the zebrafish. I. Number, morphology, and histochemical characteristics of neurons in the locus coeruleus. J Comp Neurol 344:242-255.

Ma P (1994b) Catecholaminergic systems in the zebrafish. II. Projection pathways and pattern of termination of the locus coeruleus. J Comp Neurol 344:256-269.

Marcus JN, Aschkenasi CJ, Lee CE, Chemelli RM, Saper CB, Yanagisawa M, Elmquist JK (2001) Differential expression of orexin receptors 1 and 2 in the rat brain. J Comp Neurol 435:6-25.

Mignot E, Taheri S, Nishino S (2002) Sleeping with the hypothalamus: emerging therapeutic targets for sleep disorders. Nat Neurosci 2002:1071-1075.

Nieminen ML, Brandt A, Pietila P, Panula P (2002) Expression of mammalian RF-amide peptides neuropeptide FF (NPFF), prolactin-releasing peptide (PrRP) and the PrRP receptor in the peripheral tissues of the rat. Peptides 11:1695-1701.

Ohkubo T, Boswell T, Lumineau S (2002) Molecular cloning of chicken prepro-orexin cDNA and preferential expression in the chicken hypothalamus. Biochim Biophys Acta 1577:476-480.

Pace-Schott EF, Hobson JA (2002) The neurobiology of sleep: genetics, cellular physiology and subcortical networks. Nat Rev Neurosci 8:591-605.

Panda S, Hogenesch JB, Kay SA (2002) Circadian rhythms from flies to human. Nature 417:329-335.

Panula P, Airaksinen MS, Pirvola U, Kotilainen E (1990) A histaminecontaining neuronal system in human brain. Neuroscience 34:127-132.

Peter RE, Fryer JN (1983) Endocrine functions of the hypothalamus of actinopterygians. In: Fish neurobiology: higher brain areas and functions, Vol II, (Davis RE, Northcutt GR, eds), pp 165-201. Ann Arbor, MI: University of Michigan.

Peyron C, Tighe DK, van den Pol AN, de Lecea L, Heller HC, Sutcliffe JG, Kilduff TS (1998) Neurons containing hypocretin (orexin) project to multiple neuronal systems. J Neurosci 18:9996-10015.

Rink E, Wullimann MF (2001) The teleostean (zebrafish) dopaminergic 
system ascending to the subpallium (striatum) is located in the basal diencephalon (posterior tuberculum). Brain Res 889:316-330.

Risold PY, Griffond B, Kilduff TS, Sutcliffe JG, Fellmann D (1999) Preprohypocretin (orexin) and prolactin-like immunoreactivity are coexpressed by neurons of the rat lateral hypothalamic area. Neurosci Lett 259:153-156.

Russell SH, Small CJ, Kennedy AR, Stanley SA, Seth A, Murphy KG, Taheri S, Ghatei MA, Bloom SR (2001) Orexin A interactions in the hypothalamo-pituitary gonadal axis. Endocrinology 142:5294-5302.

Sakurai T, Amemiya A, Ishii M, Matsuzaki I, Chemelli RM, Tanaka H, Williams SC, Richardson JA, Kozlowski GP, Wilson S, Arch JR, Buckingham RE, Haynes AC, Carr SA, Annan RS, McNulty DE, Liu WS, Terrett JA, Elshourbagy NA, Bergsma DJ, et al. (1998) Orexins and orexin receptors: a family of hypothalamic neuropeptides and G-protein-coupled receptors that regulate feeding behavior. Cell 92:573-585.

Saper CB, Chou TC, Scammell TE (2001) The sleep switch: hypothalamic control of sleep and wakefulness. Trends Neurosci 24:726-731.

Shibahara M, Sakurai T, Nambu T, Takenouchi T, Iwaasa H, Egashira SI, Ihara M, Goto K (1999) Structure, tissue distribution, and pharmacological characterization of Xenopus orexins. Peptides 20:1169-1176.

Sutcliffe JG, de Lecea L (2002) The hypocretins: setting the arousal threshold. Nat Rev Neurosci 3:339-349.
Thannickal TC, Moore RY, Nienhuis R, Ramanathan L, Gulyani S, Aldrich M, Cornford M, Siegel JM (2000) Reduced number of hypocretin neurons in human narcolepsy. Neuron 3:469-474.

Trivedi P, Yu H, MacNeil DJ, Van der Ploeg LH, Guan XM (1998) Distribution of orexin receptor mRNA in the rat brain. FEBS Lett 438:71-75.

van den Pol AN, Gao XB, Obrietan K, Kilduff TS, Belousov AB (1998) Presynaptic and postsynaptic actions and modulation of neuroendocrine neurons by a new hypothalamic peptide, hypocretin/orexin. J Neurosci 118:7962-7971.

Westerfield M (1995) The zebrafish book: guide for the laboratory use of zebrafish (Danio rerio), Chap 1-3, Ed 3. Eugene, OR: University of Oregon.

Whitmore D, Foulkes NS, Strahle U, Sassone-Corsi P (1998) Zebrafish clock rhythmic expression reveals independent peripheral circadian oscillators. Nat Neurosci 8:701-707.

Yamanaka A, Tsujino N, Funahashi H, Honda K, Guan JL, Wang QP, Tominaga M, Goto K, Shioda S, Sakurai T (2002) Orexins activate histaminergic neurons via the orexin 2 receptor. Biochem Biophys Res Commun 290:1237-1245.

Zhdanova IV, Wang SY, Leclair OU, Danilova NP (2001) Melatonin promotes sleep-like state in zebrafish. Brain Res 903:263-268. 